\title{
Climate Change Action and COP
}

Is it not imperative to be head strong with Climate inclusive policies?

Dr. Prachi Ugle Pimpalkhute

ESDW2021- ESDW European Wide Initiative Organizer, Lead and Mentor for Mission De Facto

Cities and Communities

Founder and Climate Change Crusader Eco Endeavourers Network,

SPP Sustainable Procurement Ambassador

UN SDG Ambassador

ACT4SDGs Ambassador, Campaigner \& Champion

Association of Commonwealth Universities Higher Education and the SDGs Network Member

UN Partnership for SDGs Platform Member

PLAY BOOK SUBMISSION TO THE COP 26 CLIMATE SUMMIT THAT WAS JOINTLY CONDUCTED BY PRESEDENCIES OF UNITED KINGDOM AND ITALY AND BEING HELD IN GLASGOW FROM 31 ${ }^{\text {st }}$ OCTOBER 2021




As Climate Change has become the focal point of discussion across all sectors, entities and cities, mainstreaming it with country's agenda be it in the parliament or via varied reporting conundrum is on all time high this decade. As leadership forays, be it as a key chair, leader, negotiator, observer, moderator, panellist, scientist, peer group or as an institutional representee - how country's spearheads or leads the negotiations and table in the discussion for better facilitation and pathway depends on its strong legislative backing. There are varied framework, methodologies and articles available as per IPCC, UNFCCC and other global compacts (GHG inventory) on the basis of which quantification and emission reductions and its trajectories are framed; however, every country's sectoral emission differs and so does the standardization. Countries do quantify, reports and places its nationalized and global commitments as per the foresaid global framework; however, a national level articulation of articles, laws, subsections, acts, bill matching with commitments is lacking. This white paper as a key dossier put forths the need for structured climate change legislation with detailed reasoning and support for its mentioning. For revolutionizing, the change for climate change - laws, decrees need to be introduced and or amended for placing commitments at the global arena strongly be at the COP (Conference of Parties) or for that matter any international intended commitments which countries commits, deals and set targets for. A specific Climate Change Act is not yet in place though climate change bill is there in few countries. When Nationally Determined Commitments (NDCs) are placed in as targets, Locally Determined Commitments (LDCs) are also to be looked for to justify our NDCs stand and moving ahead the global commitments.



Figure:1. Basic Overview of Structured Framework Legislation 
Overview layout of what the structured framework legislation shall contain

\section{Climate Change Act - Articles}

\begin{tabular}{|c||l||l||l|}
\hline \hline Article: 1.1 & Article 2.1 & Article 3.1 & Article 4.1 \\
Article: 1.2 & Article 2.2 & Article 3.2 & Article 4.2 \\
Article: 1.3 & Article 2.3 & Article 3.3 & Article 4.3 \\
\hline \hline Article: 5.1 & Article: 6.1 & Article: 7.1 & Article: 8.1 \\
Article: 5.2 & Article: 6.2 & Article: 7.2 & Article: 8.2 \\
Article: 5.3 & Article: 6.3 & Article: 7.3 & Article: 8.3 \\
\hline
\end{tabular}

\begin{tabular}{|c||c||c||c|}
\hline Section I & Section II & Section III & Section IV \\
Sub-section 1.1 & Sub-section 2.1 & Sub-section 3.1 & Sub-section 4.1 \\
Sub-section 1.2 & Sub-section 2.2 & Sub-section 3.2 & Sub-section 4.2 \\
Sub-section 1.3 & Sub-section 2.3 & Sub-section 3.3 & Sub-section 4.3 \\
\hline
\end{tabular}

\begin{tabular}{|c|c|c|c|}
\hline \multicolumn{4}{|c|}{ Pacts - Negotiations (EMISSION REDUCTION (ER) PACT) (NET NEUTRAL (NN PACT) } \\
\hline Negotiation A-I & Negotiation B -I & Negotiation C-I & Negotiation D-I \\
\hline Negotiation A-II & Negotiation B -II & Negotiation C-II & Negotiation D-II \\
\hline Negotiation A- III & Negotiation B - III & Negotiation C-III & Negotiation D-III \\
\hline Negotiation A-IV & Negotiation B- IV & Negotiation C-IV & Negotiation D-IV \\
\hline Negotiation E-I & Negotiation F-I & Negotiation G-I & Negotiation H-I \\
\hline Negotiation E-II & Negotiation F-II & Negotiation G-II & Negotiation H-II \\
\hline Negotiation E- III & Negotiation F- III & Negotiation G- III & Negotiation H- III \\
\hline Negotiation E-IV & Negotiation F-IV & Negotiation G-IV & Negotiation H-IV \\
\hline \multicolumn{4}{|l|}{ Pacts - Deals } \\
\hline $1.5^{0} \mathrm{c}$ Deal & $2^{0} \mathrm{c}$ Deal & $\begin{array}{l}\text { Zero Emission } \\
\text { Reduction }\end{array}$ & Carbon Bubble Burst \\
\hline $\begin{array}{c}\text { Cap Trade and } \\
\text { Circulate (CTC) Deal }\end{array}$ & $\begin{array}{c}\text { India } 2030 \\
\text { Decarbonization } \\
\text { and Divestment } \\
\text { Deal }\end{array}$ & $\begin{array}{l}\text { Carbon Bond } \\
\text { Hedging }\end{array}$ & $\begin{array}{l}\text { Legalized } \\
\text { Carbon Tax }\end{array}$ \\
\hline
\end{tabular}




\section{Legislative Mechanism and Framework - Methodologies}

\begin{tabular}{|c|c|c|c|}
\hline $\begin{array}{l}\text { Legally Binding } \\
\text { Climate Commitment } \\
\text { Methodology } \\
\mathrm{L}_{1} \mathrm{~B}_{1} \mathrm{CCM}\end{array}$ & $\begin{array}{l}\text { Legally Binding } \\
\text { Climate Positive } \\
\text { Commitment } \\
\text { Methodology } \\
\mathrm{L}_{2} \mathrm{~B}_{2} \mathrm{CPCM}\end{array}$ & $\begin{array}{l}\text { Legalized } \\
\text { Applicative } \\
\text { Emission Reduction } \\
\text { Methodology } \\
\mathrm{L} \mathrm{A}_{1} \mathrm{E}_{1} \mathrm{RM}\end{array}$ & $\begin{array}{c}\text { Legalized Carbon } \\
\text { Bubble Methodology } \\
\text { Framework (C1B1M) }\end{array}$ \\
\hline $\begin{array}{l}\text { Carbon, Trading, } \\
\text { Incentivization and } \\
\text { Capping } \\
\text { Methodology } \\
\text { (CTICM) }\end{array}$ & $\begin{array}{l}\text { Decarbonization } \\
\text { and Divestment } \\
\text { Methodology } \\
\text { Framework } \\
\text { (DDMF) }\end{array}$ & $\begin{array}{l}\text { Legalized Country } \\
\text { specific Carbon } \\
\text { Bonds } \\
\text { Methodology } \\
\text { LCSCBM }\end{array}$ & $\begin{array}{l}\text { Legalized Carbon } \\
\text { Tax and } \\
\text { Methodology } \\
\text { Framework (LCTMF) }\end{array}$ \\
\hline \multicolumn{4}{|c|}{ Legislative Mechanism and Framework - Tools } \\
\hline $\begin{array}{c}\text { Carbon Assessor } \\
\text { Assessment Tool Kit } \\
\text { (CAATK) }\end{array}$ & $\begin{array}{l}\text { Climate Binding } \\
\text { legalized Target } \\
\text { Questionnaire } \\
\text { Toolkit (CBLTQT) }\end{array}$ & $\begin{array}{c}\text { Emission } \\
\text { Reduction Pathway } \\
\text { Questionnaire } \\
\text { Toolkit (ERPQT) }\end{array}$ & $\begin{array}{c}\text { Scenario Building } \\
\text { Legalized } \\
\text { QuestionnaireToolkit } \\
\text { (SBLT) }\end{array}$ \\
\hline $\begin{array}{c}\text { Global Outreach } \\
\text { Negotiation } \\
\text { Questionnaire Tool } \\
\text { for COPs } \\
\text { /Pacts/Deals }\end{array}$ & $\begin{array}{c}\text { Global } \\
\text { Communication of } \\
\text { Negotiation for } \\
\text { Targets and } \\
\text { Commitments } \\
\text { OuestionnaireTool }\end{array}$ & $\begin{array}{c}\text { Global Pact } \\
\text { Signatories for } \\
\text { Deals Legalized } \\
\text { Framework Tool }\end{array}$ & $\begin{array}{l}\text { Global submission of } \\
\text { legalized tax, trade - } \\
\text { offs and offsets } \\
\text { Policies Capacity } \\
\text { Building Tool }\end{array}$ \\
\hline
\end{tabular}

\section{Climate Change Act - Articles}

Climate Change Definition: A continuous transition in weather pattern induced due to natural and anthropogenic sources affecting temperature, heat pattern, oceans, land, biodiversity and its underlying forces is defined as Climate Change

Climate Change Act: A legislative act passed with varied articles and sub-sections articulated for regulation, management and implementation for a strengthened institutional and more structured facilitation of climate change mitigation and adaptation with clear focus explanatory on its impacts.

Article 1.1: It is at the behest of legal machinery, its binding to define the reason thereof by entities, sectors and cities the way they perceive the definition of climate change in their directives.

Article 1.2: It is at the behest of legal machinery, its binding to define the impacts of climate change by entities, sectors and cities.

Article 1.3: It is at the behest of legal machinery, its binding to define the varied emission types. 
Article 2.1: It is at the behest of legal machinery, its binding on the part of entities, sectors and cities to articulate a climate change action plan.

Article 2.2: It is at the behest of legal machinery, its binding on the part of entities, sectors and cities to map their emissions, scope and screening mechanism per se of the emissions.

Article 2.3: It is at the behest of legal machinery, its binding on the part of entities, sectors and cities to place their climate change induced emission trajectories before stakeholders.

Article 3.1: It is at the behest of legal machinery, its binding on the part of country to direct the state machinery to place their action plan before the national institutional board or MoEFCC thereof.

Article 3.2: It is at the behest of legal machinery, its binding on the part of states to devise mapping their local specific emissions per se, so as to place its stand at the national level for negotiation. This article aims to foster negotiation to happen from states per se with the national authority.

Article 3.3: It is at the behest of legal machinery, its binding on the part of country to map at the country level climate change action practitioners and stakeholders so as to better facilitate the regulation, management and implementation plan.

Article 4.1: It is at the behest of legal machinery, its binding on the part of entities, sectors and cities to map their internal stakeholders across the supply chain per se for ease of communication and negotiation with nationalized institutional body.

Article 4.2: It is at the behest of legal machinery, its binding on the part of local, regional and national level, how they devise the $1.5^{\circ} \mathrm{c}$ and $2^{\circ} \mathrm{c}$ pact deal or a foresaid based on location and climate type their per degree commitments and how they shall set accord with it as target setting per se.

Article 4.3: It is at the behest of legal machinery, its binding on the part of country to map its capand-trade policy deal so as to better facilitate and get benefited with the stakeholders with which it shall negotiate and deal with. Stakeholders can be international level and or nationalized levellers, institutional network base and leadership base.

Article 5.1: It is at the behest of legal machinery, its binding on the part of country to disclose its decarbonization and divestment policy to its stakeholders including international fraternity or for that matter institutionalized partners as foresaid with whom deals and pacts were signed per se.

Article 5.2: It is at the behest of legal machinery, its binding on to bring into per view carbon bond hedging, green bonds, trade-offs and offsets under legal commitments by all the entities, sectors, cities including stakeholders and stock exchanges. This shall avoid legal litigations and penalties and at the same time curtails credit risks on the financial structure of the country.

Article 5.3: It is at the behest of legal machinery, its binding on to bring in Basel, Credit risk assessment and finance including carbon tax under legislative framework starting from local to national scale for better facilitation and implementation of nationalized commitments, strengthen insurers, assessors and auditors and also in turn strengthening the global commitments per se.

Article 6.1: It is at the behest of legal machinery, its binding to have all the entities, sectors and cities abide by the localized emission reduction commitments, zero emission commitments and Climate neutral commitments they put forth and sign a deal or accord at a decided time frame.

Article 6.2: It is at the behest of legal machinery, its binding for all the states to table in state level conference of Parties (COP) and fix a legalized time frame for its negotiation with the country legal bench.

Article 6.3: It is at the behest of legal machinery, its binding to have scenario-based simulations and emission reduction pathways legally stamped in as a country wide screening and scoping framework. 
Article 7.1: It is at the behest of legal machinery, its binding to have climate change models and its associated machinery be brought under the umbrella of MoEFCC. As entities, sector and for that matter ministry in itself liaises with varied international institutionalized partners and stakeholders to develop it.

Article 7.2: It is at the behest of legal machinery, maintain a national registry or repository of all the negotiations, deals, pacts and being a signatory including being institutionalized partners, stakeholder and lead chair, negotiator, observer and financial assessor.

Article 7.3: It is at the behest of legal machinery, its binding to have communication, outreach and capacity building of VAT and GST (CGST, including SGST) having carbon tax mentioning, (carbon tax inclusive with GST) or (GST be trimmed a bit to scope for carbon tax) to stakeholders.

Article 8.1: It is at the behest of legal machinery, its binding to have all the global negotiations, commitments and targets set per se be passed as resolution in the parliament before reaching the global fraternity for the deals and pacts.

Article 8.2: It is at the behest of legal machinery, its binding to bring in all the local, regional and city level commitments, including that by entities and sector, a foresaid matter work with country ministerial machinery for "Seal the Deal" commitments.

Article 8.3: It is at the behest of legal machinery, its binding to bring in varied legislatives on environment tabled in for discussion, amendment and to be passed as resolution for forming a single open window platform of Climate Change Regulation Committer. It shall restrengthen regulatory machinery and restrengthen future commitments, goals and targets set per se.

\section{Climate Change Act - Sub-sections}

\section{Section I}

Under section I, it shall be the responsibility or duty of every entity, sector and city to abide by the climate change act regulations.

Sub-section 1.1: Under sub-section 1.1, it shall be the bound responsibility of the entities, sectors and cities to place their climate change impacts induced due to their action in reporting framework; to avoid penalties per se.

Sub-section 1.2: Under sub-section 1.2, it shall be the bound responsibility or duty to report the varied emission types so as to avoid penalties, bailouts, get exemptions for being ethical and transparent climate change committers for reporting the emission types.

Sub-section 1.3: Under sub-section 1.3, it shall be the bound responsibility or duty to report the emission types to Ministry or Bureau for ease of incentivization and facilitation of future trajectories.

\section{Section II}

Under section II, it shall be the responsibility or bound duty of entities, sector and cities, its citizens to abide by the Climate Change Action Plan (CCAP) and bring in its application at their respective capacities for ease of access, facilitation and implementation (AFI)

Sub-Section 2.1: Under sub-section 2.1, it shall be the responsibility or bound duty of entities, sectors and cities to report and chalk out their Climate Change Action Plan (CCAP) and pass it as a legalized resolution at the state and national legal bench.

Sub-Section 2.2: Under sub-section 2.2, it shall be the responsibility or duty to map the emissions 
Sub-section 2.3: Under sub-section 2.3, it shall be the responsibility or duty of stakeholders to report their emission trajectories (quantifiable example: be it in terms of Metric tonne or $\mathrm{tCO}_{2} \mathrm{e}$ or terra joules or gigatons) to avoid penalties, avail exemptions, carbon funds, grants, subsidies, incentives, off-set credits, tradeoffs and for market sledging, trading and hedging (STH).

\section{Section III:}

Under section III, it shall be the responsibility or bound duty, a foresaid as per the country's higher legal directive every state representative shall place State Specific Climate Change Action (SSCCA).

Sub-section 3.1: Under sub-section 3.1, it shall be the responsibility or bound duty as per the country's higher legal directive, every state representative shall place State Specific Climate Action Plan (SSCCA) in the assembly for passing it as a resolution and table it for discussion and resolution at legal bench before putting it as an (for official use) at the country's institutionalized Ministerial board or MoEFCC for access, allocation and grants, waivers and for being proponents.

Sub-section 3.2: Under sub-section 3.2, it shall be the responsibility or bound duty of state machinery and leadership to map the localized emissions so as to table in for negotiations at the national level. Not necessary $2^{0} \mathrm{c}$ commitment can be applicative across all places, it shall differ based on the climate regime. This necessary in lieu as in the case of, bailouts, signoffs, backouts, withholding, backlashing, dodging of deals and negotiations.

Sub-section 3.3: Under sub-section 3.3, it shall be the responsibility or bound duty on the part of country or Government per se to map the climate change practitioners and stakeholders as legalized advocacy leaders - since they involve themselves in deals, negotiations, pacts, for accord and or discord, signoffs, layoffs, backouts, penalties and bailouts

\section{Section IV:}

Under section IV, it shall be the responsibility or bound duty on the part of country, states cities and region to map its stakeholders including internal ones. This shall be legally mandatory for ease of communication, facilitation, regulation, negotiation and implementation of climate change action and target setting.

Sub-section 4.1: Under sub-section 4.1, it shall be the responsibility of entities, sectors and cities to map its internal stakeholders across the supply for ease of communication and negotiation at the national level. Legal penalties, tradeoff layouts, tax and cess for falsified mapping as it curtails to losses on part of country's climate change action, mitigation and management machinery.

Sub-section 4.2: Under sub-section 4.2, it shall be the responsibility of state representative and leadership including the country level leadership to place in per degree $\left({ }^{0} \mathrm{c}\right.$ commitments) and set accord with target setting. Legally binding location specific ${ }^{0}$ commitments for ease of facilitation, as failure of it leads to losses amidst action future scenario building.

Sub-section 4.3: Under subsection 4.3, it shall be the responsibility and bound duty to legalize the cap-and-trade policy across all levels for ease of regulation and implementation. To reach maximized legalized benefits for tradeoffs and offsets, this is the best viable deal maker, negotiator, facilitator, moderator, chair leader, pact maker, handler, observer and steerer policy tool institutionalized leveler subsection of the act. 
Negotiation A-I: Negotiation A-I pact refers to country's adaptation agreement (CAA), which shall a foresaid include local, regional and nationalized agreement. Negotiation pact includes the following: screening, scoping, devising, debating, resolving, handling, committing, deriving at a unified consensus for regulation.

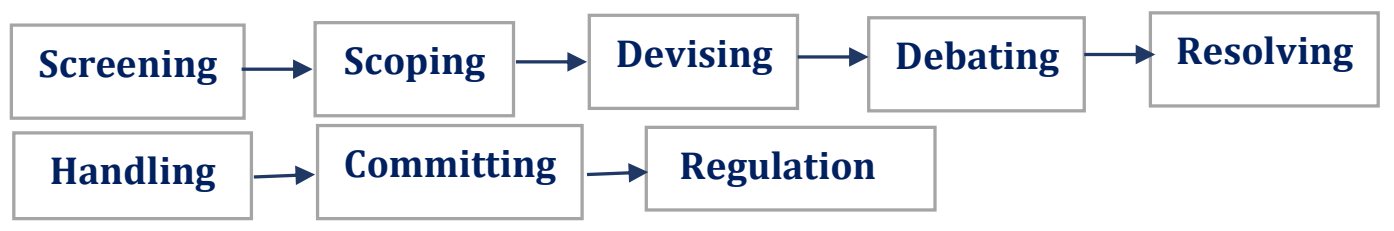

Negotiation A-II: Negotiation A- II pact refers to emission reduction adaptive applicative agreement. It shall a foresaid include Emission Reduction Adaptive Scheme, Adaptation Credits Scheme, Adaptation Tradeoff and offset policy scheme. It includes for succeeding the scheme the requirement of the following: Donor, investor, developer, modeler, insurer, auditor, key chair leader, assessor, validator.

\begin{tabular}{|c|c|c|c|c|c|c|}
\hline \multicolumn{2}{|c|}{$\begin{array}{l}\text { Emission Reduction } \\
\text { Adaptive Scheme }\end{array}$} & \multicolumn{3}{|c|}{$\begin{array}{l}\text { Adaptation Credits } \\
\text { Scheme }\end{array}$} & \multicolumn{2}{|c|}{$\begin{array}{l}\text { Tradeoffs and offset } \\
\text { policy scheme }\end{array}$} \\
\hline Donor & Investor & Developer & Modeler & Insurer & Auditor & $\begin{array}{c}\text { Key chair } \\
\text { leader }\end{array}$ \\
\hline Assessor & Valida & & & & & \\
\hline
\end{tabular}

Negotiation A III: Negotiation A- III pact refers to Adaptation and Mitigation Nationalized Compact (AMNC). This pact shall a foresaid include structured legalized binding adaptation and mitigation with focus on management aspects as well.

Adaptation and Mitigation Nationalized Compact: $\left(\mathrm{AMNC}_{1}\right)_{\text {) refers to defining the basis }}$ of adaptation and Mitigation aspects, target setting, limit setting.

Adaptation and Mitigation Nationalized Compact: $\left(\mathrm{AMNC}_{2}\right)$ refers to legalized elaborate and structured defining of adaptation and Mitigation tools and how they can be negotiated and or tabled for being a signatorv to the deal.

Structured Legalized Adaptation, Mitigation and Management Machinery pointers (SLAMMMP ) $_{\text {) }}$ refers to structured legalized commitments covering Adaptation, Mitigation and Management.

Structured Legalized Adaptation, Mitigation and Management Machinery pointers (SLAMMMP ${ }_{2}$ ) refers to structured legalized commitments covering Adaptation, Mitigation and Management with framework aspecting on how it outreaches with stakeholders.

Negotiation A -IV: Negotiation A-IV pact reters to Adaptation, IMitigation, IManagement and legalized structured financial binding commitments (AMMLSFBC), map and liaise with varied stakeholders for building future adaptation, mitigation, management and financial structures for dealing and for deriving signatory pact consensus.

Adaptation, Mitigation, Management and Structured Financial Binding commitments

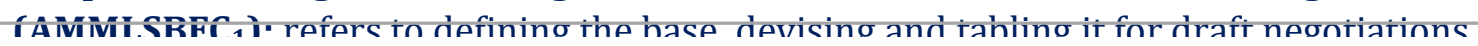

Adaptation, Mitigation, Management and Structured Financial Binding Commitments $\left(\mathrm{AMMLSBFC}_{2}\right)$ : refers to mapping the stakeholders and liaising with it for raising legalized financial funding 
Adaptation, Mitigation, Management and Legalized Structured Financial Binding Commitments with Net Neutrality Pact (AMMLSFBC ${ }_{3}$ with NN) refers to defining and devising $\mathrm{AMMSLSFBC}_{3}$ with net neutrality pact screening and scoping.

Adaptation, Mitigation, Management and Legalized Structured Financial Binding Commitments with Net Neutrality Pact (AMMLSFBC 4 with NN) refers to mapping the stakeholders for net neutrality and capacity building for better facilitation, legalized tradeoffs and cross sectoral benefitting a foresaid through proper channel (institutionalized stakeholders, institutionalized submissions to Scientific and Ministerial bodies and organizations including government machinery.

Negotiation B - I refers to legalized carbon bonds defining and aspecting the varied types of bonds which all entities, sectors and city level they can be applied including their coexistence with stock exchanges. Green bonds, Blue bonds, Grey Bonds (example For Building and Construction), orange bonds (institutional strengthening financial companies including banking domain), pink bonds (Financial skill development and educational bonds), black bonds (thermal sector), brown bonds (mining and minerals).

\begin{tabular}{|l|l|l|l|l|l|}
\hline Green Bonds & Blue Bonds & Grey Bonds & Orange Bonds & Pink Bonds & Black Bonds \\
\hline Brown & White Bonds & Red Bonds \\
\cline { 3 - 5 }
\end{tabular}

Negotiation B - II refers to legalizing the mapping of stakeholders with whom carbon bonds are forsaid laised for.

Negotiation B - III refers to binding framework pacts tabled for negotiations under strict legal judisary the carbon bonds, ledgers and carbon notch ups - this shall avoid penalties, falsification of funds and grants, bailouts, lockouts and back outs out of deals, signatories and annexes.

Negotiation B - IV refers to legalized binding of climate positive, climate neutral, zero emission commitments and defining, scoping, screening and institutionalizing it across varied stakeholders and entire supply chain for ease of facilitation and implementation. Creating Carbon Bond Niche, Carbon Bond fly paper, and binding targets tradeoff platform at local, regional and national level.




Negotiation C-I refers to legalized climate change compact - with modalities, penalities, assession at the behest of judicary for clean deal consensus and resolution.

Negotiation C - II refers to legalized climate change codes assigned to varied entities, sectors and cities based on their climate change assessment or GHG inventory database. Coding shall be legalized, more secured, not to be falsified for, transparent, not to be copied, nor reproduced theroef, legailized database for framework building of future scenarios and trajectories.

Negotiation C - III refers to legalized climate change per degree (0c commitment) agreement. The negotiation group at the behest of legalized framework define, devise, discuss, debate, resolve and or dessolve local, regional and country specific 0c commitment tabled for negotiation at the institucionalized, governing and ministerial machinery.

Negotiation C-IV refers to legalized climate change compact panelers, negotiators, key chair, member group, observers, moderators, resolvers, brain stromers, compact sealers, breaking the ice dealers incase of breakouts or back outs with the other negotiatiling peer groûps.

Negotiation D- I refers to legalized climate change decarbonization and divestment commitments. It makes it mandatory on the part of country per se to place before the local, state, regional, city, country and globai levei divestment policy machinery and trades and signatories data.

Negotiation D-II refers to legalized climate change decarbonization pathways and regulations framework which the varied entities, sectors and cities abide by. It inlcudes layoffs, mapping for insuing, penalizing, punishing, closer and back outs and blaclisting of entities and sectors not following the commitments per se which it embar ked at the level a foresaiú mentioned.

Negotiation D-III refers to passing the divestment policy as a resolution before placing or submitting at the UNFCCC institutional framework its commitments at the parliament and at the higher legal bench.

Negotiation D-IV refers to legalized cap-and-trade and circulate policy as an negotiation framework at the global arena for getting financial backing and articulation of key climate change commitments with both legal and financial binding on the principles of circular economy.

Negotiation E - I refers to legalized zero emission reduction pathway mandatory clausing on part of entities, sectors, cities, regions and localities. As is the case with NAAQSM (National Ambient Air Quality Standards and Management), National Ambient Air Quality Monitoring Stations (NAAQM)have a Climate Change Emission Monitoring, Standards and Management (CCEMSM)legal framework.

Negotiation E -II refers to legalizing Carbon bond hedging. It gives on the part of entities, sectors and cities per se to go for carbon bonds sledging via trading mechanism and framework in consultation and by passing of resolution at the judicial bench and parliament before placing as a gobal compact communication.

Negotiation E-III refers to on the part of country per se, what the government machinery must embark upon carbon bubble burst definition at the legalized level, and at what level it is explained bv varied entites. sectors and cities.

Negotiation E -IV refers to on the part of country per se, at what level carbon tax regimes and extent it is applied and implemented for tradeoffs and off sets and incentivization and how it is negotiated by the country at the global level. And much before it at the local and regional level. 
Negotiation F - I refers to on the part of country per se, Carbon Change Foreign Policy (CCFP) as an inclusive part of the Climate Change Act that needs to be drafted and formally passsed as Act or bill a forsaid.

Negotiation F- II refers to on the part of country per se, Carbon Change Foreign Trade and Offsetting Policy Framework (CCFTOPF) be made as a pact with legally binding negotiations and deals under its aegis or umbrella for country level institutionalized submission at varied international mechanism and machinery.

Negotiation F- III refers to on the part of country per se, at the behest of legalized binding commitments frame Fair Trade and Circular Economy Principle Framework (FTCEPF) for strengthening financial struture of climate change action or so to say as a matter thereof of climate change finance.

Negotiation F -IV refers to on the part of country per se, articulate and make legally binding Foreign Divestment Policy (FDP), it also makes it mandatory to have negotiation happen at state level on Decarbonization and Divestment policy once it is passed as an official resolution based framework. The same shall a foresaid be mentioned as a management policy by varied entities, sectors and cities which are constinously transiitioning in its energy commitments, use and management.

Negotiation G - I refers to on the part of country per se, frame country, state, city and site specific GHG emission inventory framework under legalized framework and it as a tool for unified application across all sectors and inventories.

Negotiation G- II refers on the part of country per se, to have ground based climate change models, Remote Sensing and GIS based models and scenario builders and Frameworks be legalized by the scientific group which develops it or for that matter government or private sector machinery which develops its standardize it for mass applicability, outreach and communication, not to be falsified or reproducible in any form thereof.

Negotiation G-III refers on the part of country per se, to have Global Compact, gaussian behaviour of emission trajectories under the umbrella of institutionalized framework. Also, thereof, make it mandatory to have behavioural study of emissions by entities, sectors and cities as with change in weather pattern, up streaming, downscaling and land use, scope and application differs. At the deal level this shall lead to ambiguity at the international level commitments.

Negotiation G-IV refers on the part of country per se make Grid based Energy Action Plan and Off-grid Energy Action Plan mandatory as a part of climate change action plan

Negotiation $\mathbf{H}$ - I refers on the part of country per se, to make it mandatory carbon risk assessment, hedonic pricing, cost benefit analyis as an integral part of reporting standards

Negotiation H - II refers on the part of country per se, to make Hybrid bonds, NDCs, science based targets,mandatory and legalized its application for availing better benefits to the stakeholders and ease of its facilitation and implementation at varied nodes, sectors, entities, sub-group annexe and non-annexe countries and farlong outreach and global communication.

Negotiation H-III refers to on the part of country per se, to have State level or city level COP be held at respective places with its representative before leading towards the global arena of COPs for signing the deal or a foresaid matter making any legally binding commitments.

Negotiation H - IV refers on the part of country per se, make it mandatory to have representatives of the country be placed for signing the accord as per the subject commitments it proposes to deal with or set accord thereof for and not as per political leadership. 
$\mathbf{1 . 5}^{\circ} \mathbf{c}$ Deal : As a part of Paris Agreement, it is legally binding goal to set limit to global warming to below $2^{\circ} \mathrm{C}$, a foresaid matter preferably to $1.5^{\circ} \mathrm{C}$. As per IPCC, UNFCC, the $1.5^{\circ} \mathrm{C}$ Paris Agreement goal is linked to a requirement in the Paris Agreement (Article 4.1): All countries work together to bring greenhouse gas (GHG) emissions to zero within the second half of the 21st century. The timing of reaching zero emissions is to be determined by the best-available science related to achieving the long-term temperature goal. That goal goes significantly further, both legally and substantively, than the earlier goal to hold warming to below $2^{\circ} \mathrm{C}$.

2.0 ${ }^{\circ} \mathrm{c}$ Deal: As per UNFCCC, IPCC - The central objective of the Paris Agreement is its long-term temperature goal to hold global average temperature increase to "well below $2^{\circ} \mathrm{C}$ above preindustrial levels and pursuing efforts to limit the temperature increase to $1.5^{\circ} \mathrm{C}$ above preindustrial levels". This is referred to by the CAT as the $1.5^{\circ} \mathrm{C}$ Paris Agreement goal. The "hold below $2 \mathrm{oC}^{\prime}$ pathways hold warming below $2^{\circ} \mathrm{C}$ with a least $66 \%$ probability and have peak 21 st century warming of up to $1.8^{\circ} \mathrm{C}$, whereas $1.5^{\circ} \mathrm{C}$ compatible mitigation pathways in IPCC SR1.5 peak warming at a significantly lower level $\left(1.5-1.6^{\circ} \mathrm{C}\right)$, and hold warming below $2^{\circ} \mathrm{C}$ with probability to at least $86 \%$.

\section{Zero Emission Reduction Pacts}

As per IPCC, UNFCCC- Net zero' means that any emissions are balanced by absorbing an equivalent amount from the atmosphere. According to the Science Based Target initiative (SBTi), "Net Zero emissions are achieved when anthropogenic emissions of greenhouse gases to the atmosphere are balanced by anthropogenic removals over a specified period."

Science Based Targets outline 3 basic principles for net zero targets to alignment with global climate goals and drive success in the net zero economy.

- Principle 1: Reaching net-zero emissions for a company involves achieving a state in which its value chain results in no net accumulation of carbon dioxide in the atmosphere and in no net-impact from other greenhouse gas emissions.

- Principle 2: In accordance with the best available science, the Paris Agreement and Sustainable Development Goals, companies should transition towards net-zero in line with mitigation pathways that are consistent with limiting warming to $1.5^{\circ} \mathrm{C}$ with no or limited overshoot.

- Principle 3: The mitigation strategy followed by the company should inform long-term strategies and investments that mitigate exposure to climate-related transition risks, ensuring that the business model of the company will continue to be viable in a net-zero economy.

As per SCiBT Recommendations for carbon setting include Boundary, Transparency, Abatement, Timeframe, Accountability, Neutralization, Compensation, Mitigation, Environmental \& Social Safeguards, Robustness.

\section{Carbon Bubble Burst}

The simmer in the temperture, due to heightened fossil fuel use results in bulge or burst of carbon or stranded assets. Its at the behest of legalized machinery to place on the carbon bubble burst avoidance pact - with Climate Coherts Framework (CCF) and Bubble Dissolving Framework and Tools (BDFT). 


\section{Cap-Trade and Circulate Deal}

Capping the $\mathrm{tCO}_{2}$ e emissions per se for devising emission reduction pathway target setting has forlong as a key climate optimistic and positive scheme. Capping it where it does not create impact is beyond BAU (Business- As-Usual) conceptualization. Trading the savings and getting credits for its postive footprint allows notched up polcy designing and structuring for buidling scenario based emissions and projections on CERs (Certified Emission Reductions) it shall gain moving ahead. Rather than infusing newer investment, tradeoffs if better capitalized can be circulated for climate commitment projects and for sectors compling by clmate change action plan in their very capacity where and how it operates. Circular economy is a newer perspective tool where in instead of the usual linear economic basis - circular economic notching up happens and if better faciliated shall bring in surplus to the entities, sectors, cities and for that matter country in itself. NDCs, CERs and NAPs, with structural financial machinery shall bring about strong Net Zero Emission Reductions targets to set in towards postive deliverables and or outcomes.

\section{Decarbonization and Divestment Deal}

Decarbonization has become a key basis for emission reduction in fossil fuel industry. Energy guzzling entities, sectors and a forsaid matter cities and the country in itself more than often keep looking in for viable options for transitioning towards clean and sustainable technologies. A key of unerlying subject of relevance to deal making depends on the following points :

1. Energy efficient devices

2. Efficient efficient management policies

3. Renewable energy effective application and implementation

4. RECs (Renewable Energy Certifications)

5. PAT (Perform Achieve and Trade)

6. Energy Action Plan

7. Energy Efficiency Policy

8. Biofuels

9. Grid based and off Grid energy efficient technologies

\section{Represenative Emisison Reduction Pathways (REPs)}

Policies / mission a like : Solar Enery Mission

Wind Energy Policy directives

Green technologies

Removing the negative emissions and restrengthening the sectors which were afloating y negative emissions towards net neutral, zero emission reduction and science based targets, Banana bonds, NDCs, National Adaptation Plan (NAP), NAMAs, MRVcs forms an integral part of decarbonization policy.

Divestment policy has become the key over the counter energy and climate positive institutionalized investment instrument with aforesaid sections for better faciliation and immplementation of policy and the postive impacts that it shall place it and aset acccord with the varied stakeholders.Divestment policy deal more than often plaes stroong institutionalized investment backed Adaptation and Mitigation Plan, setup and implementation.

\section{Carbon Bonds Hedging}

Climate change action has over the decade a transitioned long way from mere aving emission inventorories, methodologies, frameworks to equivocal consensus Hedging the emissions at the most safest level ; circumventing the emissions which it can by induction policies and subject concern a foresaid mentioned above. Varied bonds and to which nodes of entities and sector it shall be 


\section{Legalized Carbon Tax}

As is the case of, with varied taxes available in the financial machinery, its at the behest of legalized machinery carbon taxes has also come under the perview of sustainable fianancial machinery for revolvitionary strong climate and energy competent commitments.

As is the case with VAT and GST, carbon tax allows better product responsibility (PR) among the manufacturing firms and its associated stakeholders who depend upon it. India is yet to have a formalized and as a part of financial machinery carbon tax slabs on the goods and services which render impact on the environment. A slab based tax criteria if drafted for products we buy in will keep resource stewardship as well as product responsibility as a key criteria element. @ so and so percentage criteria if a consensus on how much tax be a best fit one will also help in quality asssessment of emissions, as a product or service which causes maximized damage shall need that much of resource or so to say energy for reduce, recovery and recovery - life cycle assessment of product.

As a part of National Action Plan for Climate Change (NAPCC), leveying Carbon tax be made a legalized instrument and be formally ratified and tabled in when India represents at the Conference of Parties, at Glasgow, UK for the Climate Change Summit in November, 2021.

\section{Over view of Framework Instrument - For Legalized Carbon Tax Mandatory Induction}

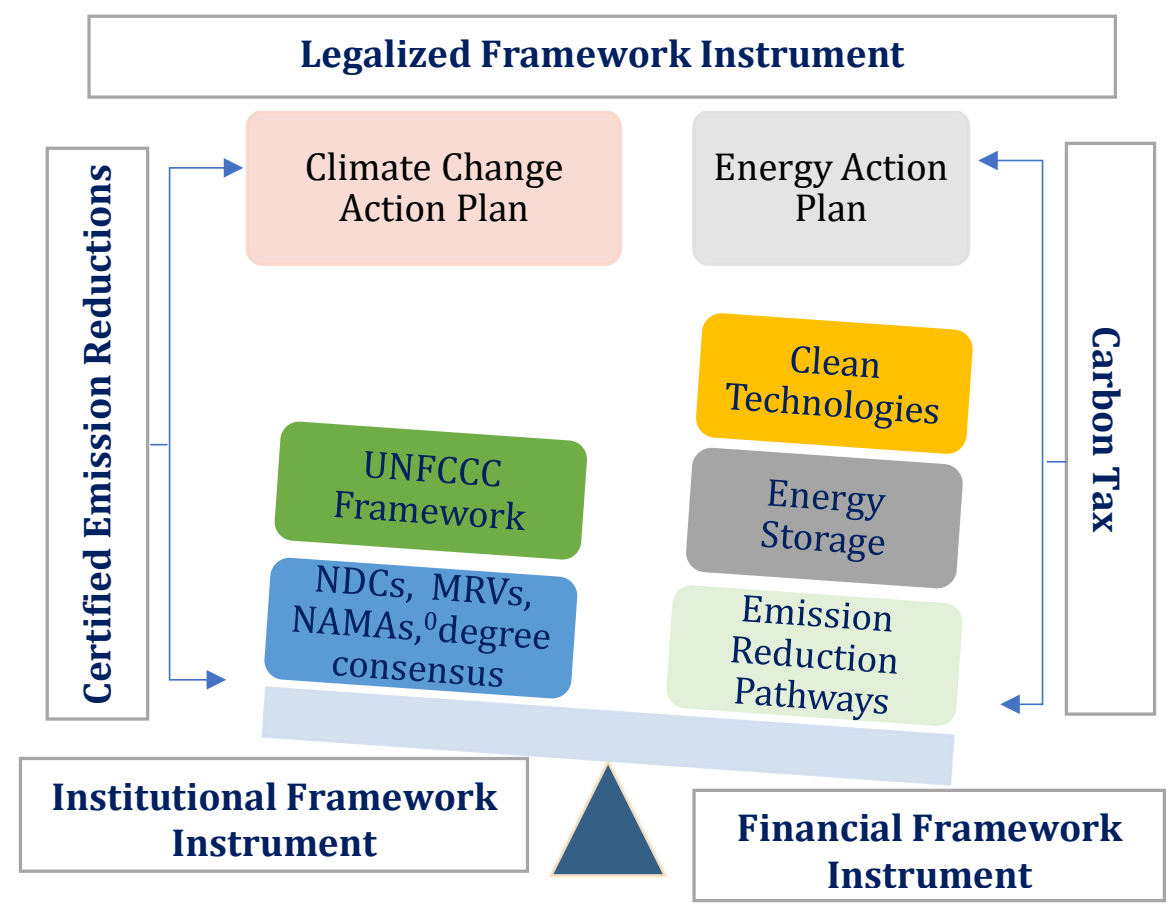

Carbon Tax Implemenation Example Scenario - For mainstreaming Individual Climate Change Impact Assessment (ICCIM) commitment Framework / Environment Damage Commitment : Suppose we opt for an incandscent blub at the time of purchase; a basic GST is added to the bill, however for CTI as per ICCIM a part of @ GST should be made inclusive of carbon tax or a separate mention of carbon tax be done. And if one opt for CFL or an LED it shall be exempted either from GST or as foresaid carbon tax. If this concept is applied to entities and sector, it shall help track, montior and better manage climate intensive notches with legalized 
backing for closure of negative emissions or Climate Non-Compliant Entities and Sectors.At city level too, Climate Non-Compliance Cities framework can e devised, where in for non-compliance with emission standards, government at the behest of judicary machinery penalize it. And in case of emission reduction for entities, sectors and cities exemptions can be granted.

\section{Legislative Mechanism and Framework - Methodologies}

Legally Binding Climate Commitment Methodology $\left(\mathrm{L}_{\mathbf{1}} \mathbf{B}_{\mathbf{1}} \mathrm{CCM}\right)$ : In this mechanism framework, entities, sectors, cities, regions and local governing bodies and or councils are made to fill a legal binding preset questionnaire before it charters its complaince with climate neutral or zero emissive trajectories.

LBMC Legally bounded to place the type of material or resource it shall use towards its climate commitment.

LBTU Legally bounded to place on record the type of technology used or applied to produce it. Whether climate sensitive/intenstive or any use of Best Available Technologies is being done as part of climate commitment. BAT be made a legalized technology for implemenation.

Legally Binding Climate Commitment Clause 1.1

Legally Binding Climate Commitment Clause 1.2

Legally Binding Climate Commitment Clause 1.3

Legally Binding Climate Commitment Clause 1.4

Legally Binding Climate Commitment Clause 1.5

Legally Binding Climate Commitment Clause 1.6

Legally Binding Climate Commitment Clause 1.7

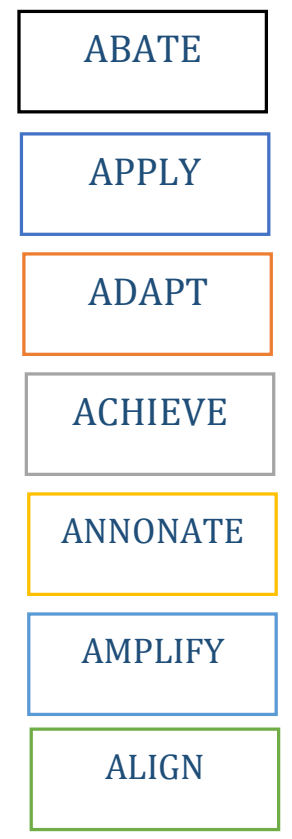

\begin{tabular}{|c|c|c|c|}
\hline $\begin{array}{c}\text { Emission } \\
\text { Reduction Law } \\
\text { based Climate } \\
\text { Commitment }\end{array}$ & $\begin{array}{l}\text { Certified Emission } \\
\text { Reduction Law } \\
\text { based Climate } \\
\text { Commitment }\end{array}$ & $\begin{array}{l}\text { Non-Compliance } \\
\text { Climate Law }\end{array}$ & $\begin{array}{c}\text { Climate Regulatory } \\
\text { Aadaption Framework } \\
\text { Law - shall include }{ }^{0} \mathrm{C} \\
\text { commitment law }\end{array}$ \\
\hline
\end{tabular}

\section{Legalized Applicative Emission Reduction Methodology $\mathrm{L}_{\mathbf{1}} \mathrm{E}_{\mathbf{1}} \mathrm{RM}$}

Sum of all the emissions quantified * Emission Factor + Legal Binding emission reduction target set (For Entities, sectors, cities, states, reions and localities) $=$ Applicative climate compliant Notching

+ Compliance

- Compliance

\pm Compliance

Eauivocal Compliance 


\section{Legally Binding Climate Commitment Methodology $\left(\mathrm{L}_{2} \mathrm{~B}_{2} \mathrm{CCM}\right)$}

\section{Legnlized Carbon Bubble Methodology Framework (C1B1M)}

Its the behest of legalized machinery to place on the carbon bubble burst avoidance pact - with Climate Coherts Framework (CCF) and Bubble Dissolving Framework and Too (BDFT).

Carbon bubble burst with technology abated fossil Fuel use

Carbon bubble burst without technology abated fossil Fuel use

Simmer in temperature rise

Drop in temperature rise

\section{Climate Coherts Framework (CCF):}

Legalized collaboration (LC),

Memorandum of Understanding (MoU)

Joint Interaction, Facilitation and Implementation (JIFI)

Inclusice Stakeholder Connect, Forum and Engagement (ISCFE)

together form a Climate Coherts Framework under the legal machinery.

Compliance with $1.5^{\circ} \mathrm{c}$ deal and its coorelation with no bubble burst

Non- Compliance with $1.5^{\circ} \mathrm{c}$ deal and its coorelation with bubble burst

Compliance with $2^{\circ} \mathrm{c}$ deal and its coorelation with no bubble burst

Non- Compliance with $2^{0} \mathrm{c}$ deal and its coorelation with no bubble burst

Decarbonization and Divestment Methodology Framework (DDMF) - includes the policy based framework methodology with varied decarbonizing tools aligned.

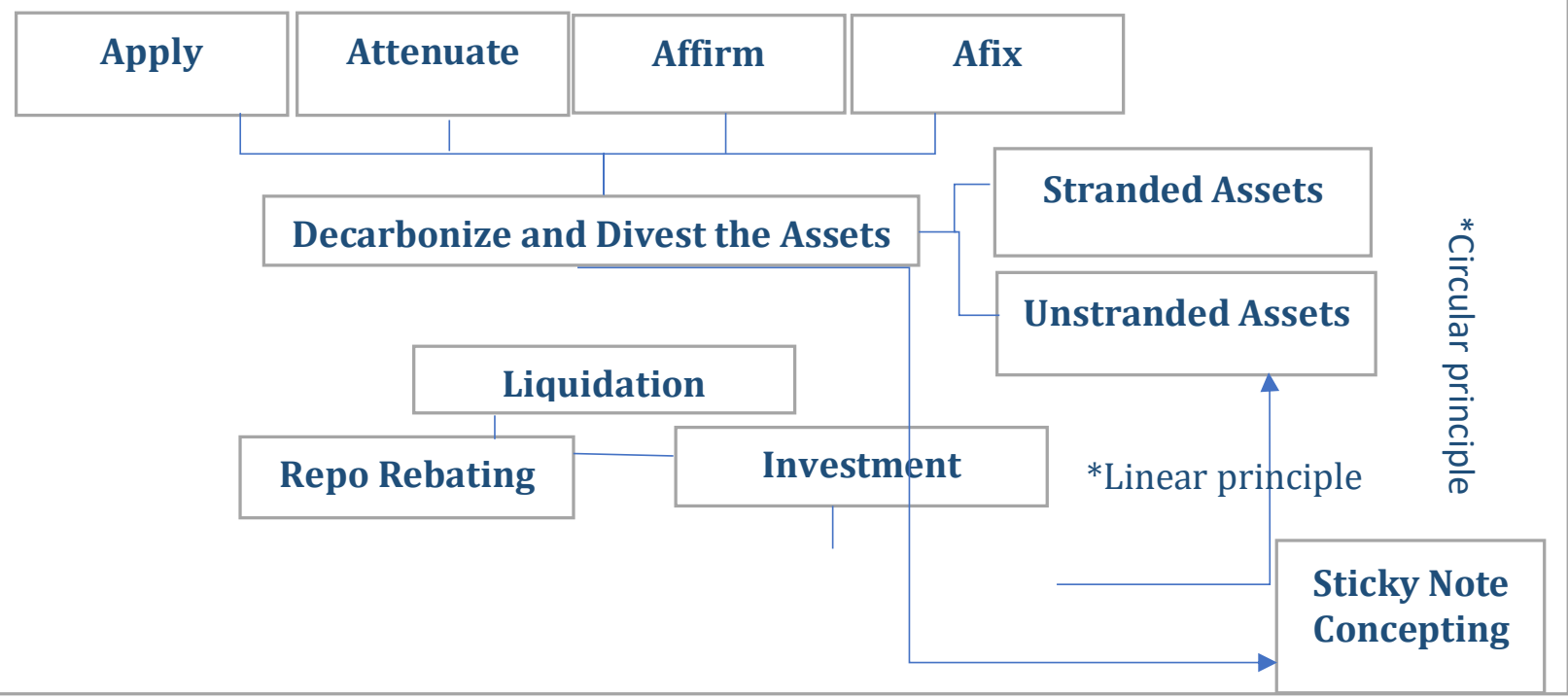




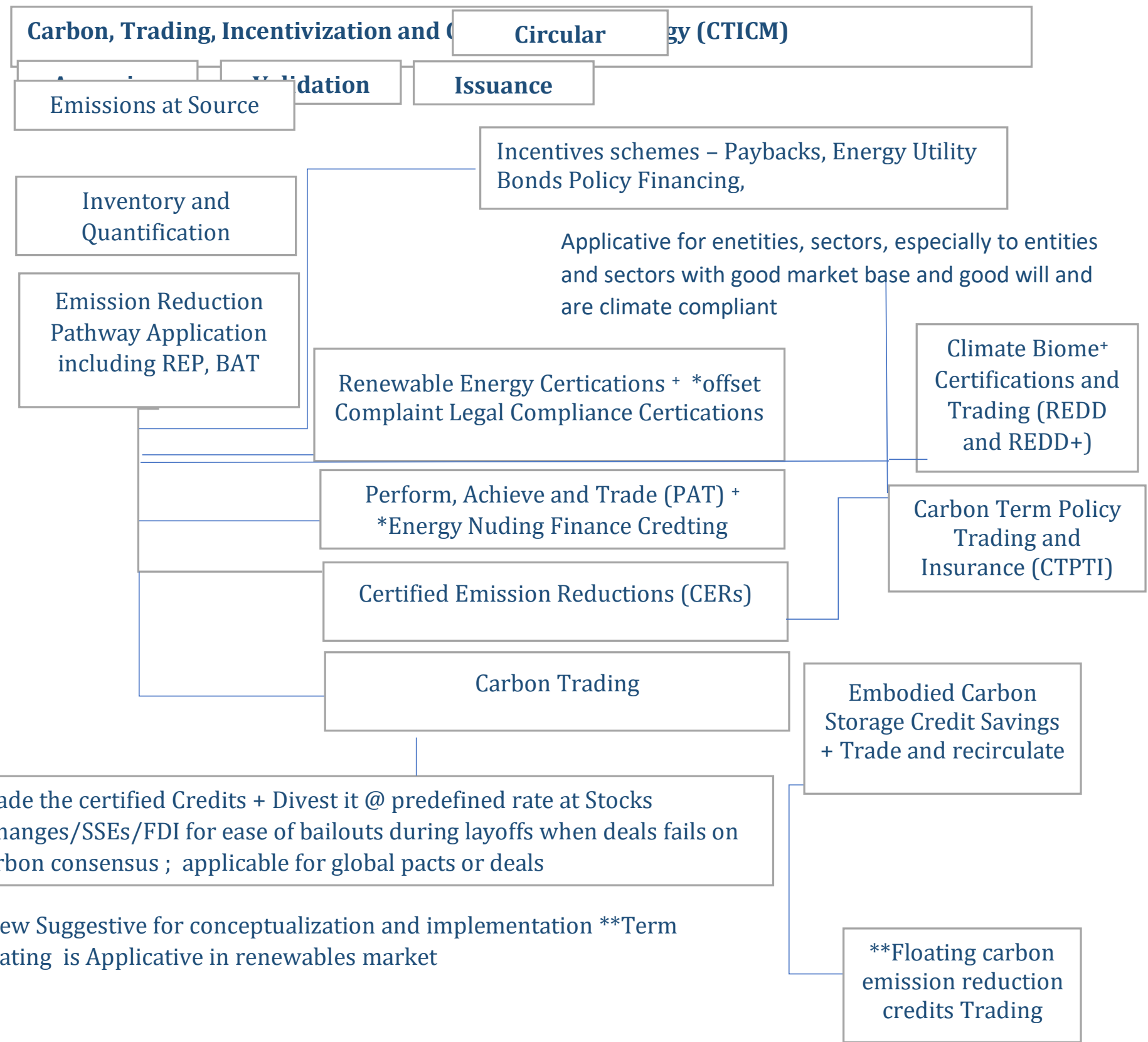

\section{Bubble dissolving framework and tools (BDFT)}

Legalizing the use of climate competent materials parts and resources thereof, as is done with regard to eco labelling schemes for products (FSCI board based, made from recycled, reuse and recovered mentioning), level of recyclability mentioning number. The use of concealers, reducing agents, softners, use of temperature reducing agents shall form the centre stage of bubble dissolving framework.

LCCP (Legally Climate Compliant Products) labelling tools. 


\section{Legalized Country specific Carbon Bonds Methodology LCSCBM}

\begin{tabular}{|c|c|c|c|c|c|}
\hline $\begin{array}{c}\text { Bonds Applicative } \\
\text { For }\end{array}$ & \multicolumn{2}{|c|}{$\begin{array}{l}\text { Mention type of entities, sector } \\
\text { including cities, states, regions } \\
\text { and locales or localities }\end{array}$} & \multicolumn{3}{|c|}{$\begin{array}{l}\text { Type of Bonds (Green, } \\
\text { Blue, Pink, Grey, Orange, } \\
\text { Black and Brown) }\end{array}$} \\
\hline \multirow{2}{*}{\multicolumn{2}{|c|}{$\begin{array}{l}\text { Special Bonds: Hybrid Bonds, Floating Bonds, } \\
\text { Utility Bonds, Hedge Bonds, Ledger Bonds, } \\
\text { Rebate Bonds, Trickle and Flutter Bonds (Fly } \\
\text { Bonds), Gem Bonds }\end{array}$}} & INSURE & INVE & & INNUND \\
\hline & & INSUADE & \multicolumn{3}{|c|}{ INTOROGATE } \\
\hline & & \multicolumn{2}{|c|}{ INFILTERATE } & \multicolumn{2}{|c|}{ INCUBATE } \\
\hline & & INTERMING & ATE & & JTRUDE \\
\hline & \multicolumn{3}{|c|}{ Sale, Resale, Invest and Reinvest } & & \\
\hline
\end{tabular}

\section{Legalized Carbon Tax and Methodology Framework (LCTMF)}

\begin{tabular}{|c|}
\hline List of Entities and Sectors \\
\hline $\begin{array}{c}\text { Define Carbon Tax application } \\
\text { (What neccesiates it ?) }\end{array}$ \\
\hline $\begin{array}{c}\text { Predefine tax slabs for each of } \\
\text { the types }\end{array}$ \\
\hline $\begin{array}{c}\text { Tax Criteria Elements: } \\
\text { Prioritizing - When, Where, } \\
\text { Which? }\end{array}$ \\
\hline $\begin{array}{c}\text { Justification : @ VAT, GST, } \\
\text { Cess, and Carbon Tax }\end{array}$ \\
\hline Apply \\
\hline Validate \\
\hline Verify \\
\hline Implement \\
\hline
\end{tabular}




Legislative Mechanism and Framework - Tools

Carbon Assessor Assessment Tool Kit (CAATK) :

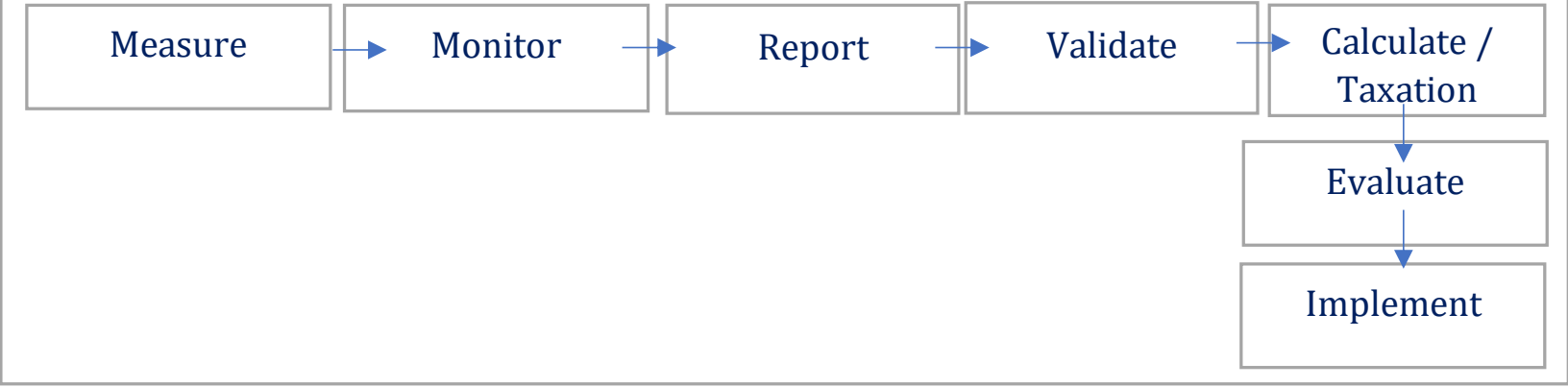

\section{Climate Binding legalized Target Questionnaire Toolkit (CBLTQT)}

Climate binding questionnaire toolkit includes :

- What is the level of understanding of climate binding from the legal perspective does the entities, sectors, cities, states, regions and localities have?

Low, Medium, High, Very High

- What is the level of application does the entities, sectors, cities, states, regions and localities does?

Low, Medium, High, Very High

- What is the level of understanding of methodologies to carry out implemenation by entities, sectors, cities, states, regions and localities does?

Low, Medium, High, Very High

- What is the level of emission reductions does the entities, sectors, cities, states, regions and localities do?

Low, Medium, High, Very High

\section{Emission Reduction Pathway Questionnaire Toolkit (ERPQT)}

- What is the level of understanding of emission reduction pathways (REP, MRVs, NAMAs, NAPs, NDCs does the entities, sectors, cities, states, regions and localities have?

Low, Medium, High, Very High

- What is the level of Certified Emission Reductions (CERs) gained by the entities, sectors, cities, states, regions and localities?

Low, Medium, High, Very High

- What is the extent of carbon tax understanding amidst the entities, sectors, cities, states, regions and localities?

Low, Medium, High, Very High

- What is the level of understanding of carbon trading and cap - trade and circulate pact including carbon bubble burst among the entities, sectors, cities, states, regions and localities?

Low, Medium, High, Very High 


\section{Scenario Building Legalized Questionnaire Toolkit (SBLT)}

- What is the level of undertsanding and how the $1.5^{\circ} \mathrm{C}$ deal is benchmarked and applicable by the entities, sectors, cities, states, regions and localiities?

Low, Medium, High, Very High

- What is the level of undertsanding and how the $2.0^{\circ} \mathrm{C}$ deal is benchmarked and applicable by the entities, sectors, cities, states, regions and localiities?

Low, Medium, High, Very High

- What is the level of understanding of emission scenario building studies, models and pathways by the entities, sectors, cities, states, regions and localiities?

Low, Medium, High, Very High

- What is the level of screening, scoping, scoping and application of scenario trajectories done by the entities, sectors, cities, states, regions and localiities?

Low, Medium, High, Very High

\section{Global Outreach Negotiation Questionnaire Tool for COPs /Pacts/Deals}

- At what level does country participates in global negotiations at the global level? Low, Medium, High, Very High

- At what level does outreach of deals, pacts, climate binding targets, goals, pacts, deals, policies being done with stakeholders?

Low, Medium, High, Very High

- At what level does outreach of legalized commitments to be abided at the behest of country directive done by the state, regional and local machinery?

Low, Medium, High, Very High

- At what level does outreach of legalized commitments to be abided at the behest of country directive done by the state, regional and local machinery?

Low, Medium, High, Very High

\section{Global Communication of Negotiation for Targets and Commitments Questionnaire Tool}

- At what level of communication the discussion of negotiations that shall happen at the global level does the country head representative does with its members, governing councils and ministerial portfolio?

Low, Medium, High, Very High

- At what level of communication the legalized binding targets implemented communicated to varied stakeholders?

Low, Medium, High, Very High 
Global Pact Signatories for Deals Legalized Framework Tool

Plan

Prepare

Communicate

Discuss

Report

Verify

Validate

Legalized Framework Instrument

Place for SEAL THE DEAL at the Negotiation Table

Global submission of legalized tax, trade -offs and offsets Policies Capacity Building Tool

Plan

Prepare

Validate

Report and Create Formalized Legal Instrument

Circulate the legalized instrument to varied Stakeholders - Questionnaire

Request for Participation and Feed Back

Create Capacity Building Tool Kit

Request for Capacity Building Workshop to the Stakeholders

Rate and submit the Capacity Building conducted to the Country Head Portfolio 